\title{
Towards Scientific Literacy for Basic School Pupils: Which Profile Dimensions are Emphasised in the Ghanaian Basic Science Curricula?
}

\author{
Ghartey-Ampiah, J. \\ Institute of Education, University of Cape Coast, Ghana
}

\begin{abstract}
This paper examines the extent to which the specific objectives in the basic school science curricula reflect the notion of scientific literacy as envisaged by the curriculum developers. The specific objectives for teaching, learning and assessment were analysed using a consensus building approach to identify objectives addressing the three profile dimensions emphasised in the two curricula. The findings revealed that far more emphasis is put on knowledge and understanding in the upper primary and junior secondary school science curricula than the curriculum developers had intended. Also, the anticipated percentage weights of the three profile dimensions are inconsistent with what obtains in the two curriculum documents. The curriculum developers therefore need to address the issue of how much content is necessary to emphasise the development of science attitudes and process skills at the primary school level and application of knowledge at the junior secondary school level as envisaged.
\end{abstract}

Key words: scientific literacy; basic science curricula; profile dimensions

\section{Introduction}

The world is gradually becoming a science-oriented global village. This means that citizens of both developing and developed countries must have a certain level of science literacy to be able to cope with the demands and problems of a science-oriented society in the context of their lives outside school. To a large extent therefore, compulsory science literacy lessons taught in school particularly at the primary and junior secondary school (JSS) levels will benefit pupils in their everyday life if properly designed.

The emphasis on providing science education for all students in an attempt to make citizens scientifically literate, gained currency with the writings of Hurd (in 1958) and others. The writings of Hurd espoused the need to teach science to all students irrespective of whether they will pursue careers in science or not (Bybee \& Deboer, 1994). This brought to the fore the notion of scientific literacy. Since that time, many countries including the United States and United Kingdom have been grappling with the type of scientific literacy appropriate for its citizens and the extent to which they must learn science in school at various levels of the education ladder to become scientifically literate.

Generally, literacy can be considered as the ability to read, listen, speak, write, communicate and reason (Kuoba \& Champagne, 1998). Applying this notion of literacy to science has resulted in different understandings or perspectives and multiple definitions of scientific literacy. For example, two prominent professional societies, American Association for the Advancement of Science (AAAS) and National Research Council (NRC) have produced documents which have defined scientific literacy from different perspectives. The AAAS notion of scientific literacy is published in Science for All Americans (1989) and Benchmarks for Science Literacy (1993) whilst the NRC document called National Science Education Standards was published in 1996.

Analysis of the NRC (1996) and AAAS (1993) documents by Kouba and Champagne (1998), shows that both documents place more emphasis on knowing principles than the application of principles. 
However, they differ on the emphasis on knowing principles when it comes to communication and reasoning. In addition, the definition of scientific literacy in the AAAS document incorporates ideas from science, technology and mathematics which is not the case in the NRC document.

Brown, Reveles and Kelly (2005) have categorised the various perspectives of scientific literacy into knowledge-centered and sociological-centered. According to them, the knowledge-centered perspective defines scientific literacy in terms of content standards in the specific science subjects with emphasis on knowledge and understanding of scientific concepts; science as inquiry; science processes and practices; and the nature and history of science. The sociological-centered perspective on the other hand emphasises a socio-cultural view of knowledge and conceptualise scientific literacy in terms of the process of learning to become scientifically literate rather than what has to be learnt to become one (Brown, et al., 2005). The sociological-centered perspective emphasises reading and writing of science texts and discursive exchanges among members of a discourse community to enact scientific events in social contexts (Langer, Applebee \& Nystrand, 1995; Brown et al., 2005). Also, the knowledgecentered perspective emphasises the acquisition of knowledge transmitted through language as preparation for individuals to engage in social activities, whilst the sociological-centered perspective emphasises the use of language as the means for individuals to participate in social activities that employ knowledge (Brown et al., 2005). Language is therefore central to both knowledge-centered and sociological-centered perspectives of scientific literacy. However, the categorization of scientific literacy into sociological and knowledge-centered perspectives is just one of several ways of classifying scientific literacy. Scientific literacy has also been categorised in terms of levels such as learned, competent, and capable of minimal function (Venezky, 1990) or personal, professional and educational contexts (Kuoba \& Champagne, 1998). Scientific literacy therefore, has many facets and different understandings or categorisations.

Even though the importance of scientific literacy is now acknowledged worldwide, attempts by the scientific community at defining scientific literacy to serve as curriculum goals for science teaching and learning especially at the basic or elementary school level and determine what should constitute its content have proved to be elusive in many countries (Shamos, 1995; Sutman, 1996). There are different opinions on what constitutes scientific literacy because the concept is wide and spans from the notion of citizens ability to describe, explain, and predict natural phenomena; read with understanding articles about science; analyse and evaluate scientific evidence, and arguments consistent with those of the scientific community among others (National Science Council, 1996; Germann \& Aram, 1996).

What an individual should know and be able to do, to be described as scientifically literate is therefore very contentious. Science taught in schools in most parts of the world to enable learners become scientifically literate even at the compulsory school level concentrate very heavily on content knowledge (scientific concepts, laws, principles and theories), development and methodology of science, with very little or no attention paid to science literacy that enables students to cope with the application of science in order to make informed judgments about issues in their daily lives which have bearings on science (Kouba \& Champagne, 1998). This is because even though many science curricula at the basic school level have very useful descriptions of the goals of science education they go beyond these goals to include unrealistic goals of science for all children at this level. Attempts to delineate what aspect of science are important for all students to learn and what should be studied beyond basic science literacy which will be beneficial to students who will not go on to offer careers in science has proved illusive to curriculum developers in many countries.

It seems every country or educational system must define scientific literacy in a way that will serve the scientific and technological needs of its citizens or students and develop curriculum and benchmarks which will enable learners achieve. Scientific literacy that is offered to students as scientific literacy by the science curriculum particularly at the primary and junior secondary school levels must be relevant to their needs as some of them will not encounter science again in a formal way after basic school education. 
Ghana like many other countries the world over does not want its citizens to be left behind in this era of rapid global scientific and technological age. Its national science curricula at the upper primary and junior secondary school levels outline the nature of science knowledge and abilities that characterise the scientifically literate person as well as the nature of teaching and assessment practices. The scientific literate person at this level is defined in the curriculum documents in terms of acquisition of scientific knowledge, ability to communicate scientific ideas, and the development of scientific attitudes and process skills. This is appropriate because scientific literacy is not only about subject content knowledge but also about critical thinking, cognitive and metacognitive abilities, and communication to share understandings to persuade others (Yore, 2001). The science curricula thus emphasise the knowledge-centered perspective of scientific literacy contained in the curriculum documents at the basic school level. The notion of scientific literacy is that of a life-long process of learning which go beyond the school system. There is also emphasis on students developing an inquiry attitude to life and living a healthy quality life.

The development of scientific process skills, manipulative skills, scientific attitudes, understanding of environmental issues, and the application of science emphasised by the Ghanaian primary and junior secondary school science curricula to define scientific literacy at the basic school level are appropriate. .these areas have been the goals of science education with relative emphasis on one aspect or the other. The curriculum documents however, do not describe explicitly the standards pupils should achieve in order to be scientifically literate at the primary and JSS levels.

The ability to communicate implies that pupils will be able to express scientific ideas through the use of the English language which is the medium of instruction and communication at both upper primary and junior secondary school (JSS) levels. According to the curriculum documents, to be able to study science effectively at the primary and junior secondary school levels, pupils should have good reading and communication skills, and mathematical skills (MOE, 2003; MOE, 2001). This requirement is in order since language is central to scientific literacy. Pupils will experience great difficulty in learning science if they have to struggle with poor literacy and communication skills in the English language.

The curricula emphasis the concept of profile dimensions which is considered the central aspect of the curricula and is expected to be the basis for instruction, learning and assessment. Three profile dimensions have been specified in the primary science curriculum with relative emphasis for each profile dimension expressed in percentage weights as follows:

$\begin{array}{ll}\text { Knowledge and Understanding } & 20 \% \\ \text { Application of Knowledge } & 20 \% \\ \text { Attitudes and Process Skills } & 60 \%\end{array}$

The emphasis on attitudes and process skills with the highest percentage weight $(60 \%)$, means that it is the most important profile dimension in teaching, learning and assessment at the primary school level. The JSS science curriculum has different relative emphasis on the three profile dimensions from that of the primary school as follows:

$\begin{array}{ll}\text { Knowledge and Understanding } & 30 \% \\ \text { Application of Knowledge } & 40 \% \\ \text { Attitudes and Process Skills } & 30 \%\end{array}$

The emphasis is more on application of knowledge than attitudes and process skills or knowledge and understanding. The reasons assigned by the curriculum developers for this different relative emphasis from that of the primary school science is that "while pupils were expected to start acquiring scientific attitudes and process skills at the primary level, the emphasis at the JSS level is to get pupils to be more science application oriented" (MOE, 2001, p. ix). 
Attitudes Ghanaian primary and junior secondary school children need to develop through the study of science suggested in the science curricula are curiosity, perseverance, flexibility in ideas, respect for evidence, and reflection. Process skills include planning, designing an experiment, observation, manipulation, measuring, evaluating, generalising, and communication. For each sub-topic in the two curriculum documents, expectations in the form of specific objectives are stated with suggested activities as a guide for the teacher. It is these specific objectives which are expected to reflect the different percentage weights of profile dimensions as specified in the primary and JSS science curricula. The curricula also have general objectives for each section (major topic) to guide the teacher. There are also suggested activities to enable children engage in reflective thinking, and hands-on learning, as well as perform experiments. The goal is to promote the acquisition of higher-order thinking skills, science attitude and process skills in primary school and JSS pupils.

\section{Purpose of the study}

The purpose of this study was to identify specific objectives for science literacy related to the three profile dimensions specified in the primary and JSS science curricula and to calculate the proportion of these objectives which reflect the three different profile dimensions. This was done through content analysis of the upper primary and JSS science curricula. The study focused on three main questions:

1. What proportion of specific objectives address the three profile dimensions in the upper primary and JSS science curricula?

2. What is the distribution of the three profile dimensions across grade levels in upper primary and JSS?

3. What is the distribution of the three profile dimensions within grade levels in upper primary and JSS?

\section{Content Analysis}

The classification of specific objectives reflecting the three profile dimensions in the science curricula was done by the researcher and two other science educators. Each person independently classified all the specific objectives in both curricula using the three profile dimensions as the basis for classification. The curriculum documents describe clearly what action verbs constitute each component of the three profile dimensions. The search for specific objectives related to the three profile dimensions was therefore guided largely by the definitions contained in the curricula. For example, "revise" is classified as application of knowledge in the curricula and so anytime this word was encountered in the statement of specific objectives it was classified as such.

There were a few action verbs (draw, devise, write, build, and determine) which were contained in the specific objectives but not stated in the curricula to describe any of the profile dimensions. Clarity was sought from the teaching/learning activities for the meaning of the few action verbs to determine how they should be classified.

The results of the independent classification were then compared and discussed by the three science educators to reach a consensus. Most objectives had only one action verb but a few contained two or three action verbs. The number of action verbs determined the count of specific objectives and not just the number of objectives. 


\section{Results and Discussion}

\section{Proportion of specific objectives addressing the three profile dimensions in the primary school and JSS science curricula}

The first question addressed was the relative proportion of emphasis on the three profile dimensions in the science curricula to see how they reflect on the intentions of the curriculum developers. Content analysis shows that the primary school science curriculum has a total of 77 units (sub-topics) and 313 specific objectives spread across primary 4 to primary 6 . Primary 5 has the most sub-topics (28) followed by primary 4 (27) and primary 6 (22). The JSS science curriculum has a total of 49 sub-topics and 365 specific objectives spread across JSS1 to JSS3. JSS2 and JSS3 have 18 sub-topics each whilst JSS1 has 13 sub-topics.

In both primary and JSS science curricula science content knowledge and science process skills seems to be separated instead of being integrated around a given sub-topic. Due to this separation, analysis of the primary school science curriculum shows that the emphasis is heavily tilted towards the acquisition of knowledge and understanding (67.1\%), followed by attitude and process skills $(20.4 \%)$ and then application of knowledge (12.5\%). This trend does not conform to the percentage weights of $20 \%$ knowledge and understanding, $60 \%$ attitude and process skills and 20\% application of knowledge spelt out in the primary school science curriculum. The mismatch of the intentions of the curriculum developers and what actually pertains in the curriculum is illustrated in Figure 1. The figures shows that knowledge and understanding in the primary science curriculum is more than three times what the curriculum developers intended it to be, whilst attitudes and process skills make up only a third of what was intended. Attitudes and process skills which is expected to be the dominant profile dimension is emphasised strongly only on 'Living things' which is one out of the 14 major topics. About two-fifths of the 64 specific objectives on attitudes and process skills in the entire curriculum fall under "Living things" with the rest shared among the remaining 13 major topics.

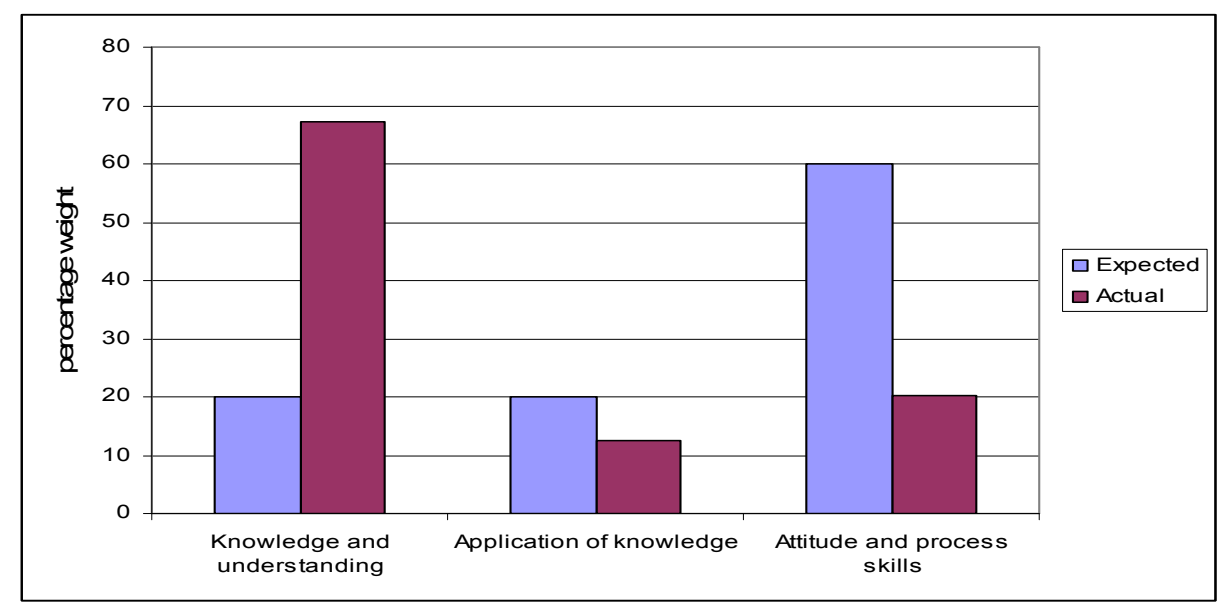

Figure 1

\section{Expected and actual percentage weights of the three profile dimensions in the primary school science curriculum}

In the case of the JSS science curriculum, content analysis shows that as it was in the case of the primary school curriculum, emphasis is heavily tilted towards the acquisition of knowledge and understanding $(69.9 \%)$, followed by attitude and process skills $(20.5 \%)$ and then application of knowledge $(9.6 \%)$. This trend is similar to that of the primary school curriculum and does not conform to the expected percentage weights of 30\% knowledge and understanding, 30\% attitude and process skills and $40 \%$ application of knowledge. Figure 2 compares the expected and actual percentage weights for the three profile dimensions. Knowledge and understanding in the curriculum is more than 
twice what the curriculum developers intended it to be whilst the percentage weight of attitudes and process skills is a little less than intended in the JSS science curriculum.

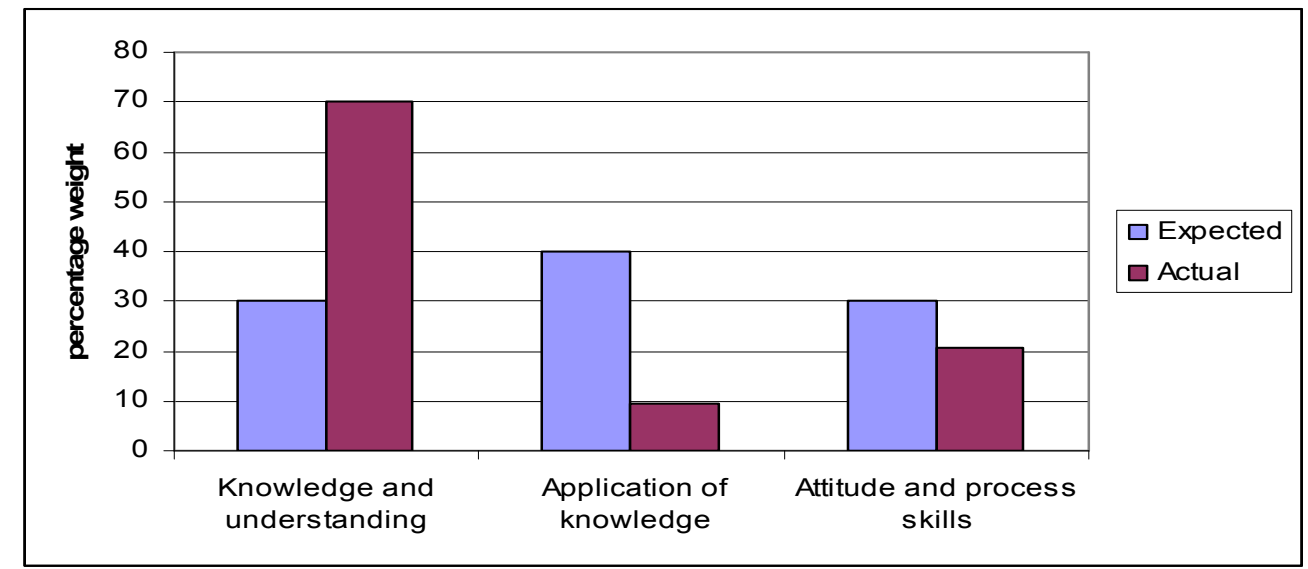

Figure 2 Expected and actual percentage weights of profile dimensions in JSS science curriculum

The proportion of specific objectives on application of knowledge is the least $(9.6 \%)$ even though it should have been the greatest (40\%). If the expectation of the curriculum developers was to get JSS pupils to be more science application oriented then that cannot be achieved with a percentage weight of application of knowledge less than one-fourth what was intended.

For teachers to assess students on what has been taught, the curriculum developers expect them "to sample the objectives within units and sections to be able to develop a test that accurately reflects the importance of the various skills taught in class" (MOE, 2001, p. vii). This means that since the emphasis of the specific objectives does not reflect the expected percentage weights of different profile dimensions, it is also likely that teaching and assessment will not follow the expected relative percentage weights if teachers go strictly by the specific objectives for each topic.

Learning for scientific literacy as described in the curricula requires more emphasis on open-ended activities that investigate relevant science questions; provide opportunities for scientific discussions among students; promote understanding and its application to new situations; skills of investigation; encourage data analysis and communication among others (National Science Education Standards, 1996). However, this could be better achieved if too much emphasis is not placed on acquisition of content knowledge at this level. Even though the intention of the curriculum developers was to put less emphasis on knowledge and understanding compared to the other two profile dimensions at both primary and JSS levels, they could not achieve it in the design due to the many topics they put into the two curricula.

Statements of specific objectives that use words which connotes communication such as distinguish, compare, describe, analyse, explain, and give reasons make up $86(27.5 \%)$ out of the 313 specific objectives in the primary school science curriculum and $130(35.6 \%)$ of the 365 specific objectives in the junior secondary school science curriculum. This modest emphasis on communication particularly at the upper primary school level means that pupils should be able to use the English language to express their ideas in science since that is the vehicle of communication at the upper primary and junior secondary school levels.

The curricula also contain suggestions and exercises for evaluating each sub-topic. Again these exercises are predominantly on knowledge and understanding $(66.5 \%)$ followed by application of knowledge (19.1\%), and attitudes and process skills (14.4\%) in the primary school science curriculum. In the case of the JSS science curriculum, action verbs which reflect knowledge and understanding in 
the suggested evaluation exercises constitute $76.6 \%$ out of a total of 192 objectives. Application of knowledge is $18.2 \%$ followed by attitudes and process skills $(5.2 \%)$. Clearly the strong emphasis on knowledge and understanding in these exercises does not resonate with the intentions of the curriculum developers themselves. This is because according to the curriculum developers, these suggested exercises and similar ones teachers are expected to give are to challenge students to apply their knowledge to issues and problems as well as encourage them to develop solutions, and positive attitudes towards science. This view demands that emphasis on suggested exercises has to be placed more on application of knowledge in the case of JSS science and attitudes and process skills in the case of upper primary school science. The curriculum developers however, have rather placed more emphasis on knowledge and understanding at both levels contrary to claims of viewing science as fostering students' curiosity about their environment and science application oriented, which could develop their intrinsic interest in things around them to be willing to "analyse problems, suggest solutions etc. and criticise solutions offered, justify solutions and evaluate the worth of possible solutions" (MOE, 2003, p. ix).

Nevertheless, there are a few good examples of exercises on process skills in both the primary and junior secondary school science curricula. Two examples are shown in Box 1 for primary schools science.

\section{Box 1 Examples of suggested exercises on 'weather' and 'kinds of fruits'}

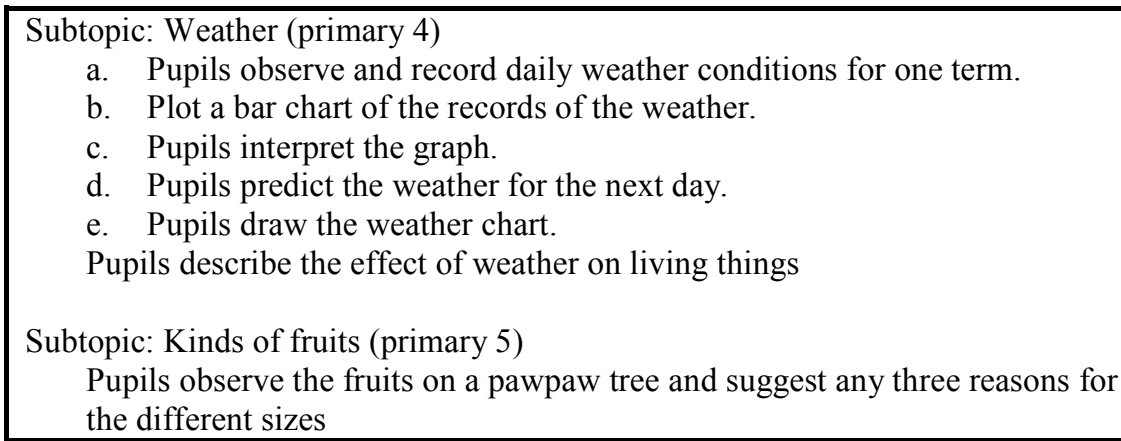

However, it is doubtful whether primary school teachers will be interested in setting more of such exercises given that the curriculum rather puts more emphasis on knowledge and understanding. Even within the curriculum document itself, most of the exercises are of the type shown in Box 2. The specific objectives primary school pupils are expected to master after going through the sub-topics and the type of evaluation exercises suggested by the curriculum developers point strongly to the teaching and learning of laws, theories, principles, and how to define, describe and explain them.

\section{Box 2 Some typical examples of suggested exercises}

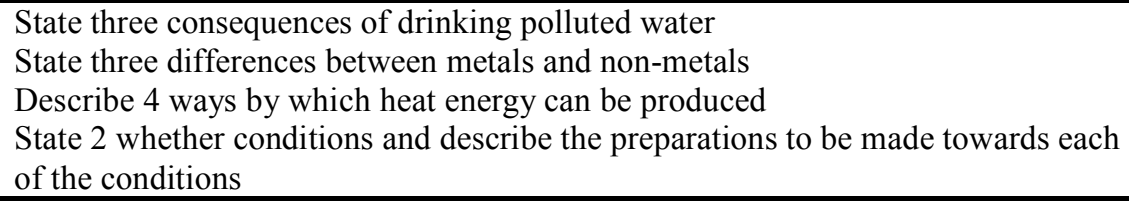

The JSS science curriculum also contains similar good examples of evaluation exercises as shown in Box 3. However, as it is in the primary school science curriculum, most of the exercises are of the type shown in Box 4. Some evaluation exercises in the JSS science curriculum look vague making it difficult to determine the purpose of the exercises. An example is shown in Box 5. First of all there is no need to identify a person who wets his/her bed whether in class or elsewhere as it is undesirable. Secondly, 
Towards Scientific Literacy for Basic School Pupils: Which Profile Dimensions are Emphasised in the Ghanaian Basic Science Curricula? Ghartey-Ampiah, J.

what is meant by 'develop a system' is vague. At best pupils can discuss some of the ways of controlling bedwetting for children of different age groups.

Box 3 Example of suggested evaluation on "light energy"

Pupils to construct a Pin Hole Camera and use the camera to take the picture of an object and compare with a picture of the object taken by a modern camera Source: MOE (2001)

\section{Box 4 Some typical examples of suggested exercises}

Mention the two types of pollination and explain the differences between them.

Describe the stages of fertilization in the Flamboyant/Pride of Barbados

State five features that make the dispersal of seeds and fruits possible.

Source: MOE (2001)

\section{Box 5 An example of evaluation exercise on excretory system of humans}

Project: Each pupil to identify a person who wets his/her bed and develop a

system by which this person can be counseled to stop bedwetting.

Source: MOE (2001)

The two science curricula contain a large number of suggested practical activities to help teachers achieve the specific objectives for each topic. However, outcomes different from those stipulated in the specific objectives could be achieved given that the focus of some of the activities are different from the specific objectives stated for the sub-topics. These outcomes if achieved would merely be accidental since they would not have been targeted by teachers. Teachers may even not know that pupils have achieved those outcomes.

\section{Distribution of the three profile dimensions across grade levels}

The results of the examination of the distribution of knowledge and understanding, application of knowledge, and attitudes and process skills across grade levels in the primary school science curriculum is shown in Table 1. The curriculum contains a total of 210 specific objectives on knowledge and understanding from primary 4 to primary 6 . Table 1 shows a gradual increase in the proportion of knowledge and understanding as pupils move from primary 4 to primary 6 . There are 64 specific objectives related to attitudes and process skills across the three grade levels, and the distribution is highest in primary 5 and lowest in primary 6 . The proportion of specific objectives on attitudes and process skills in primary 5 is more than double that in primary 6 .

Table 1 Distribution of profile dimensions across the three upper primary grade levels

\begin{tabular}{lcccccccc}
\hline & \multicolumn{9}{c}{ Grade level } & & \\
& Primary 4 & Primary 5 & Primary 6 & Total \\
& No. & \% & No. & \% & No. & \% & No. \\
\hline Knowledge and understanding & 57 & 27.1 & 73 & 34.8 & 80 & 38.1 & 210 \\
Application of knowledge & 14 & 35.9 & 15 & 38.5 & 10 & 25.6 & 39 \\
Attitudes and process skills & 23 & 35.9 & 28 & 43.8 & 13 & 20.3 & 64 \\
\hline
\end{tabular}


This is partly because there are more topics and specific objectives for primary 5 than primary 6 . A similar trend is observed for the 39 objectives reflecting application of knowledge across grade levels. This means that more emphasis is placed on the acquisition of knowledge and understanding of subject matter at the last level of primary school. However, as children mature from primary 4 to primary 6 , the expectation is that the amount of learning in the area of process skills and attitudes, and application of knowledge should have progressively increased instead of decreased. This would have resonated with the intentions of the curriculum developers.

The proportion of knowledge and understanding, application of knowledge, and attitudes and process skills across grade levels in the JSS science curriculum is shown in Table 2. The curriculum contains 255 specific objectives on knowledge and understanding from JSS1 to JSS3. Table 2 shows a gradual increase in the proportion of this profile dimension from JSS1 $(32.5 \%)$ to JSS2 (37.3\%) and a decrease to $30.2 \%$ in JSS3, which is even below that of JSS1.

Table 2 Proportion of profile dimensions across the three JSS grade levels

\begin{tabular}{|c|c|c|c|c|c|c|c|}
\hline & \multicolumn{6}{|c|}{ Grade level } & \multirow{3}{*}{$\begin{array}{r}\text { Total } \\
\text { No. }\end{array}$} \\
\hline & \multicolumn{2}{|c|}{ JSS1 } & \multicolumn{2}{|c|}{ JSS2 } & \multicolumn{2}{|c|}{ JSS3 } & \\
\hline & No. & $\%$ & No. & $\%$ & No. & $\%$ & \\
\hline Knowledge and understanding & 83 & 32.5 & 95 & 37.3 & 77 & 30.2 & 255 \\
\hline Application of knowledge & 16 & 45.7 & 9 & 25.7 & 10 & 28.6 & 35 \\
\hline Attitudes and process skills & 19 & 25.4 & 28 & 37.3 & 28 & 37.3 & 75 \\
\hline
\end{tabular}

This means the emphasis on knowledge and understanding is relatively de-emphasised in JSS3. This being the case, one would have expected that the percentage weight of application of knowledge will be higher in JSS3, since the curriculum developers suggests an emphasis on this profile dimension at the JSS level. A look at Table 2 shows that even though the proportion of application of knowledge is higher in JSS3 than JSS2, it is far higher in JSS1 than JSS3. Thus, the distribution of percentage weights of the various profile dimensions across grade levels does not seem to follow any discernable pattern. This is contrary to what is stipulated in the JSS science curriculum. The idea of promoting application of knowledge above the other two profile dimensions is therefore not supported by the distribution of profile dimensions across grade levels as shown in Table 2.

As children mature from primary 4 to primary 6 it is expected that their mastery of the English language will improve, making them able to express themselves better. If this is true, then there should have been more specific objectives which reflect communication in primary 6 than in primary 5 and primary 4 in that order. This is however, contrary to what the analysis shows. The analysis shows that out of the 94 specific objectives in primary $4,29.8 \%$ use action verbs, which suggest communication (describe, explain, give reasons, show how, analyse) compared to $27.6 \%$ out of 116 specific objectives in primary 5 , and $25.2 \%$ out of 103 specific objectives in primary 6 .

Again, there should have been more specific objectives reflecting communication in JSS3 than in JSS2 and JSS1 in that order. The emphasis on communication is rather more in JSS1 than JSS3. Out of the 118 specific objectives in JSS1, 39.0\% use words which suggest communication compared to $32.6 \%$ out of 132 specific objectives in JSS2, and 35.7\% out of 115 specific objectives in JSS3.

\section{Distribution of the three profile dimensions within grade levels}

Figure 3 shows the distribution of percentage weights of profile dimensions within each grade level at the upper primary school. The figure shows that the emphasis on the three profile dimensions within primary 4 and primary 5 is quite similar, even though the number of objectives related to the profile dimensions is different. The figure shows a ratio of $61: 24: 15$ for primary 4 and 63:24:15 for primary 5 
(knowledge and understanding: attitude and process skills: application of knowledge). A similar trend is not seen in primary 6 which has a ratio of 77:12:10. However, within each grade level there are far more specific objectives on knowledge and understanding than the other two profile dimensions.

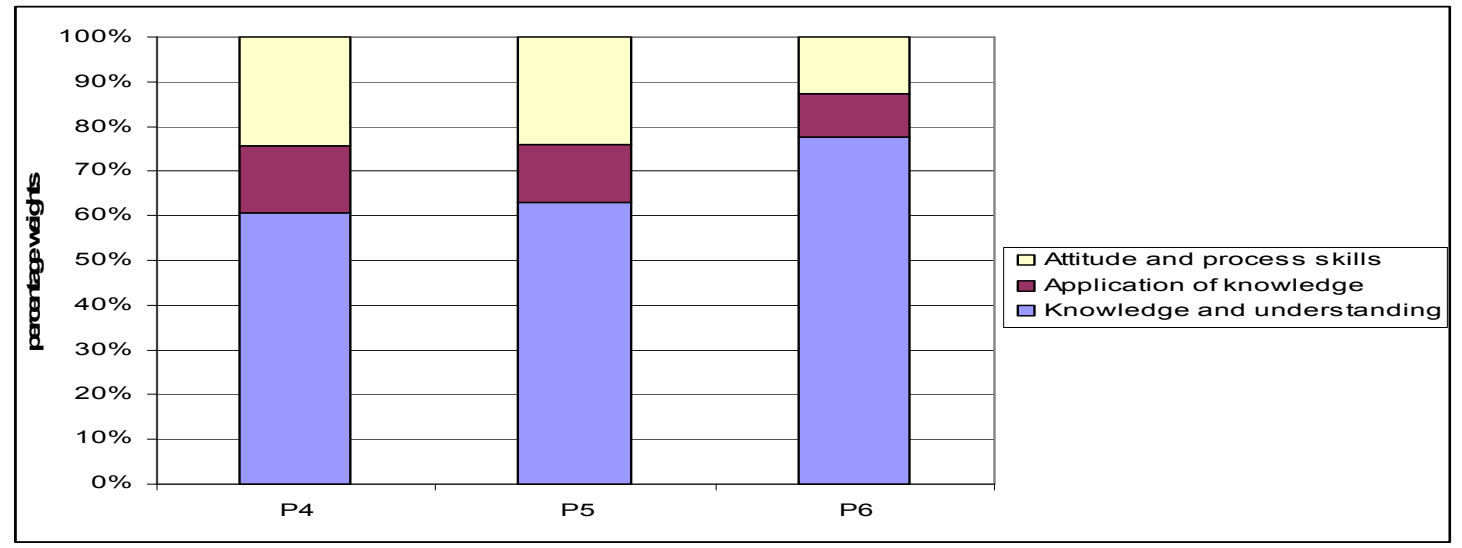

Figure 3 Distribution of percentage weights for profile dimensions within each grade at the primary school level.

Figure 4 shows the distribution of percentage weights for profile dimensions within each JSS grade level. The figure shows that the proportion of specific objectives on knowledge and understanding within JSS1 and JSS2 is quite similar. Also the proportion of specific objectives related to application of knowledge within JSS2 and JSS3 are also similar. However, within each grade level more emphasis is placed on knowledge and understanding, followed by attitude and process skills, and then application of knowledge. Specific objectives related to the application of knowledge make up the lowest proportion at each JSS grade level contrary to the expectation expressed by the curriculum developers. The picture that emerges from Figure 4 is rather that of more emphasis on knowledge and understanding in each JSS grade level (70:14:16 for JSS1; 72:9:21 for JSS2; and 67:9:24 for JSS3), which is also the case for the upper primary level.

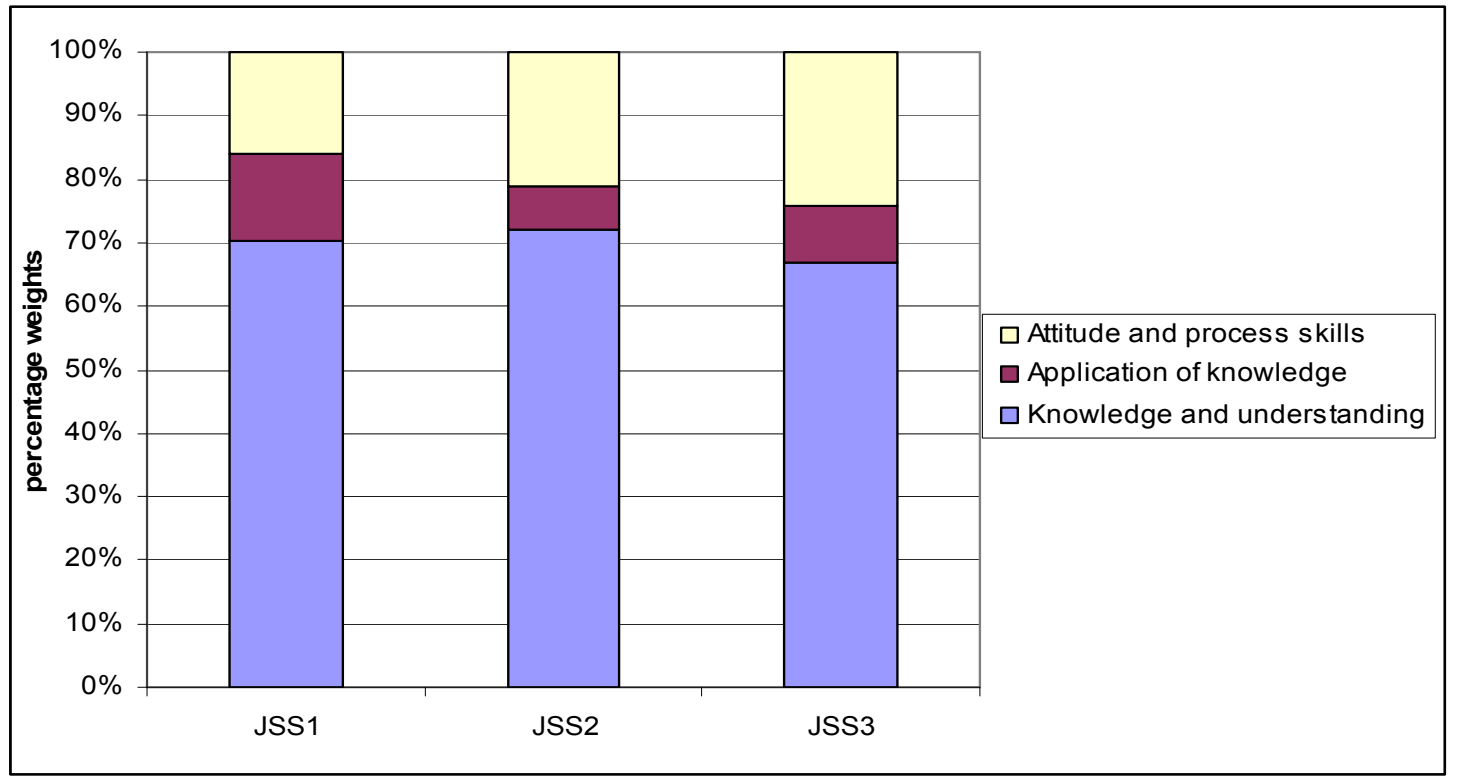

Figure 4 Distribution of percentage weights for profile dimensions within each grade at the JSS level 
The picture that emerges from both primary and JSS science curricula is that far less emphasis is put on application of knowledge relative to the other profile dimensions in each grade level. Since teachers are expected by the curriculum developers to go by the specific objectives for each sub-topic for teaching, learning and testing, this trend will send the wrong signals to teachers or even confuse them as to the relative emphasis which must be placed on the three profile dimensions at each grade level.

\section{Implications}

The curriculum developers have suggested, five periods (150 minutes) of science teaching per week at the primary school level. Given the heavy content to be covered in the upper primary school science curriculum, if teachers go strictly by the recommended time, they would have to teach roughly one subtopic each week to be able to cover the more than 20 sub-topics at each grade level, given that the time includes periods of assessment and feedback to pupils. At the JSS level, the suggested time four periods of 35 minutes each (140 minutes) per week. The time allocation permits roughly one and half weeks fro teaching each topic. It is therefore unlikely for teachers who for one reason or the other teach less than the stipulated periods per week to be able to cover the curricula especially in primary 5 , which has 28 sub-topics. The curricula for primary and JSS may need more time to cover than anticipated by the curriculum developers.

Also, be able to cover large amounts of content, teachers are more likely to conduct fewer practical activities. So even though the curricula contain a lot of practical activities, most of them will be confined to one lesson at a time instead of putting more emphasis on investigations over extended periods of time. For example, teachers will not see the need to let pupils to observe and record daily weather conditions for one term as shown in Box 1 if all that will be assessed is the recall of facts or some rehearsed explanations and descriptions. This is because teachers will not see the need to use practical activities to enable pupils state, define, classify, describe, explain, label etc. Teachers will undoubtedly use the structured approach to teaching to achieve most of the specific objectives since they are on knowledge and understanding. However, current thinking about teaching and learning of science emphasises the inquiry method and social constructivism-that learners construct their own knowledge and understandings based on what they already know and the socio-cultural context in which they find themselves (EFA Global Monitoring Report, 2005). This approach is very suitable for helping pupils develop positive attitudes and process skills through hands-on and minds-on activities which the curriculum developers appear to encourage. However, given the different profile dimensions in the curricula, teachers will need to adopt multiple approaches to teaching.

If the teaching of science at the upper primary and junior secondary school levels will follow the inquiry-oriented approach using activities as the curriculum developers have suggested, then more sophisticated teaching skills than those associated with traditional didactic methods must be employed by teachers. Teachers must therefore, be given time and opportunity to develop their repertoire of professional skills for teaching science content and process skills through in-service education and training (INSET). Teachers must also have time to reflect, evaluate, and adequately prepare and participate in ongoing learning/professional development with their colleagues. This opportunity could also be provided through school-based INSET.

Learning takes time and is usually not instantaneous. Children therefore need sufficient time (beyond the 60 to 70 minutes of each lesson) to reflect on their ideas, play with them, and use them in order to develop their conceptual understandings of lessons which emphasise the process of investigation and inquiry through practical activities (Gunstone, 1995) as suggested by the science curricula. This cannot happen in a 60-70 minute lesson which is the maximum time a primary school or JSS science lesson is expected to last. Unfortunately, the adoption of the solely behaviourist approach to teaching all subjects by the Ghana Education Service (GES) in the Ghanaian education system with statements like By the end of the lesson students will be able to... which is "premised on simplistic behaviourist assumptions of stimulus-response" (Akyeampong, Pryor \& Ampiah, 2006, p.162), and used in writing lesson plans in 
basic schools is inconsistent with the inquiry-oriented and constructivist perspective of teaching approach the science curriculum developers seek to promote. Science process skills take time to develop and will not fit into the straight jacket of pre-determined behavioural objective

es with its time bound requirements as stipulated by the GES. Also, trying to embed inquiry and activity-oriented science lessons in a context of traditional prescriptive instructional teacher behaviour with curricula, which accidentally emphasise acquisition of content knowledge most of which is at the knowledge and understanding level, is a major problem.

The enormous emphasis put on knowledge and understanding means that pupils would need to learn and remember a lot of information and hence the use of science textbooks by both teachers and pupils is of utmost importance. Also, literacy in science requires that children learn to read science text. This also means that pupils should be made to read or look through their science textbooks in class under the instruction of their teachers during some of the science lessons as a starting point to reading scientific materials in future. Given the dearth of textbooks in Ghanaian basics schools (pupil-core-textbook ratio fell from 1:1.7 from 2003 to 1:1.4 in 2004 [MOEYS, 2004]), the availability and use of science textbooks for science lessons is a big challenge to the education system. This means that on the average each pupil has only one textbook instead of one each for mathematics, science and English language which is the government's target.

Finally, since both curricula make it explicitly clear that good skills in reading, communication and mathematics are pre-requisite for learning science at both upper primary and junior secondary school levels, emphasis must be placed on developing these skills in children at the lower primary school. Language in particular is emphasized by Vigotsky (1978) as being inextricably intertwined with learning and since language is an important component of scientific literacy, it cannot be ignored. Fortunately, communication is one of the cardinal pivots of scientific literacy and it is emphasised in the science curricula at primary and JSS levels. Given that primary school pupils' proficiency in English language especially in public schools is abysmally low (Lipson \& Wixson, 2004; Criterion Reference Test, 2000), efforts must be made to enable pupils learn and use of English language in the study of science.

\section{Conclusion}

The Ghanaian upper primary and JSS science curricula with its many topics and sub-topics and the limited time allocated to complete it can best be described as overcrowded with content. It is therefore not surprising that there is little emphasis on attitude and processes skills at the primary school level and application of knowledge at the JSS level as envisaged by the science curriculum developers. The philosophy of the curriculum developers on the relative importance of the three profile dimensions does not match the structure of the curricula. Teachers will therefore be confused as to where the emphasis must be laid. The curriculum documents separate science knowledge and science processes instead of integrating them around a given science content area. In doing this the study has shown that emphasis is heavily tilted towards the acquisition of knowledge and understanding. This is because the science curricula appear to be providing access to basic scientific literacy for all students as well as first stage training in science for students who will go on to study science-related careers in future. This is very difficult to achieve in practice. The result is that the suggested percentage weights of the three profile dimensions by the curriculum developers are not consistent with what appear in the design of the two curriculum documents.

Instead of letting children learn a few fundamental science concepts and use them to develop attitude and process skills, and application of knowledge, the curriculum developers rather inadvertently put more emphasis on knowledge and understanding due to the large number of content topics introduced into the curricula. If the intention of the curriculum developers is to move teaching and learning from the didactic acquisition of knowledge and rote memorization to the situation where pupils will be able 
to "apply their knowledge, develop analytical thinking skills, develop plans, generate new and creative ideas and solutions, and use their knowledge in a variety of ways to solve problems" (MOE, 2001), then they need to revisit the science curricula. The curriculum developers have to address the issue of how much content is necessary at the primary school and JSS levels to promote the development of science process skills and attitudes (planning, observation, evaluation, communication, respect for evidence, reflection etc.), and application of knowledge (application, analysis, synthesis and evaluation) if that is what the curricula really intend to achieve.

\section{References}

Akyeampong, K., Pryor, J. \& Ampiah, J.G. (2006). A vision of successful schooling: Ghanaian teachers' understandings of learning, teaching and assessment. Comparative Education, 42 (2) $155-176$.

American Association for the Advancement of Science, Project 2061 (1989). Science for All Americans. New York: Oxford Press.

American Association for the Advancement of Science, Project 2061 (1993). Benchmarks for science literacy. Washington, DC: American Association for the Advancement of Science.

Brown B. A., Reveles, J. M, Kelly, G. J. (2005). Scientific Literacy and Discursive Identity: A Theoretical Framework for Understanding Science Learning. Published online 30 June 2005 in Wiley InterScience (www.interscience.wiley.com)

Bybee, R.W. \& Deboer, G. (1994). Research on the goals for science education. In D.L. Gabel (Ed.), Handbook of research on teaching and learning of science (pp. 357-387). New York: Macmillan.

Criterion Reference Test (2000). Report on the Administration of P6 Criterion Reference Test. Accra: Ministry of Education.

EFA Global Monitoring Report (2005). Education for all: The quality imperative. Paris: UNESCO.

Germann, P., \& Aram, R. (1996). Student performances on the science processes of recording data, analyzing data, drawing conclusions, and providing evidence. Journal of Research in Science Teaching, 33, 773- 798 .

Gunstone, R. F. (1995). Constructivist learning and the teaching of science. In B. Hand \& V. Prain (Eds.). Teaching and learning in science: The constructivist classroom (pp. 3-20). Sydney: Harcourt Brace.

Kouba, V.L. \& Champagne, A.B. (1998). Literacy in the national science and mathematics standards: Communication and reasoning. Report Series 3.14. Retrieved June 16, 2006, from www.eric.ed.gov/ERICDoc/data/ericdocs2/contentstorage

Langer, J.A. Applebee, A.N., \& Nystrand, M. (1995, December). Technical proposal for National Research and Development Center in student learning and achievement in English. Albany, NY: University at Albany, School of Education.

Lipson, M. \& Wixson, K. (2004). Evaluation of the BTL and ASTEP programmes in the Northern, Eastern and Volta Regions of Ghana. (Report prepared for The Education Office, USAID/Ghana). Accra: USAID.

MOE (2001). Teaching syllabus for science (JSS). Accra: Ministry of Education, CRDD

MOE (2003). Teaching syllabus for integrated science (Primary 4-6.). Accra: Ministry of Education, CRDD 
Towards Scientific Literacy for Basic School Pupils: Which Profile Dimensions are Emphasised in the Ghanaian Basic Science Curricula? Ghartey-Ampiah, J.

MOEYS Ghana (2004) Education sector performance report: October 2004. Accra: Ministry of Education

National Science Council. (1996). National science education standards. Washington, DC: National Academy Press.

Parker, J. (2004). The synthesis of subject and pedagogy for effective learning and teaching in primary science education. British education Research Journal, 30 (6) 819-839.

Shamos, B. M. H. (1995). The myth of scientific literacy. New Brunswick, NJ: Rutgers University Press.

Sutman, F. X. (1996). Guest editorial: Science literacy: A functional definition. Journal of Research in Science Teaching, 33, 459-460.

Venezky, R.L. (1990). Definitions of literacy. In R.L. Venezky, D.A. Wagner, \& B.S. Ciliberti (Eds.). Toward defining literacy. (pp 2-16). Newark DE: International Reading Association.

Vigotsky, L. (1978). Mind and Society. Cambridge, MA: Harvard University Press.

Yore, L. D. (2001). What is meant by constructivist science teaching and will the science education community stay the course for meaningful reform? Retrieved June 16, 2006, from http:/unr.edu/homepage/crowther/ejse/yore.html 